\title{
Removal of Surface Damage from Focused Ion Beam using Plasma Cleaner
}

\author{
Dong-Su Ko, * Young Min Park, ${ }^{*}$ Sung-Dae Kim, * Young-Woon Kim.*
}

* School of Materials Science and Engineering, Seoul National University, Gwanak-gu Sillim-dong San 56-1, Seoul, Republic of Korea 151-744

Surface damage in the thinned samples is a bottleneck for the critical analysis in transmission electron microscopy(TEM). Ion milling conditions used in conventional sample preparation $(3 \sim 8 \mathrm{keV}, 10-30 \mu \mathrm{A})$ leave amorphous layer on the surfaces, which varies $\sim 3-6 \mathrm{~nm}$ in thickness. (make references from the table at the end) In the TEM sample prepared using Focused Ion Beam(FIB), it is more difficult to remove the surface Ga-rich layer because of the geometry of the thinned area. Low energy ion beam milling is so far the most effective way to remove the surface damage formed by either ion milling or Focused Ion Beam(FIB). Instead of using directional low energy ion beam to remove the surface damage, plasma cleaner, typically used in the analysis of scanning transmission electron microscopy (STEM) to minimize the carbon contamination, was utilized to make low energy milling effect in this study. Basic idea is to bombard the surface applying bias to the sample in the high density plasma formed by Radio Frequency wave.

Silicon wafers with 200-nm-thick oxide, formed by wet oxidation, were used in the etch rate experiment. Etch Bias voltage was changed from 100-300 V and the etching times were varied from 5 to 30 minutes. $\mathrm{SiO}_{2}$ etching rate was measured using Ellipsmeter (Gaetner, model L116C). Effectiveness of surface damage removal with the proposed technique was applied in the FIBprepared blue-laser GaN/InGaN multi quantum well sample. Cross-sectional TEM images were taken by a Tecnai F20 electron microscope.

Fig. 1(a) and (b) show removal rate of surface oxide as a function of time with a constant $200 \mathrm{eV}$ bias voltage and a function of bias with $15 \mathrm{~min}$ etch time. Removal rates increase linearly with both time and applied voltage. Fig 1(c) shows variation of removal rate with the sample position at the tip of the holder. Etching rate increases as the measured position is located closer to the plasma-generating coil. No significant etching was observed up to $15 \mathrm{~mm}$ from the holder tip as seen the figure, which may be the effect of plasma geometry around the holder tip. If the sample is located closer to the center of the plasma forming coil, much higher etching rate could be obtained. Fig. 2(a) and (b) show cross-sectional high-resolution TEM micrographs of Silicon single crystal before plasma etching and after plasma etching, respectively. The initial thickness of ion-beam-induced damage layer is $\sim 13 \mathrm{~nm}$, while the damaged layer thickness reduced to $\sim 7 \mathrm{~nm}$ after plasma etching with $70 \mathrm{~V}$ bias for $8 \mathrm{~min}$. We report a simple, easy way to clean the surface damage using plasma cleaner without going through multiple steps of ion-milling, low-energy milling, plasma-cleaning. The technique was successfully applied to FIB-prepared samples to show the effectiveness of the surface damage removal.

References

[1] Young-Woon Kim, Metals and Materials International, 5 (2001) 499

[2] A. Barna et al., Ultramicroscopy. 70 (1998) 161

[3] T.Schuhike, M. Mandl and J.Zweek, Ultramicroscopy 41 (1992) 429 
[4] C. W. T. Bulle-Lieuwma and P. C. Zalm, Surf. Interface Anal 10 (1987) 210

[5] J. C. Lee, C. S. Jeong, H. J. Kang, H. K. Kim and D. W. Moon, Appl. Surf. Sci 100 (1996) 97

[6] This research was supported by the Korea Research Foundation Grant funded by Korea Government (MOEHRD, Basic Research Promotion Fund) (KRF-2005-000-10448)
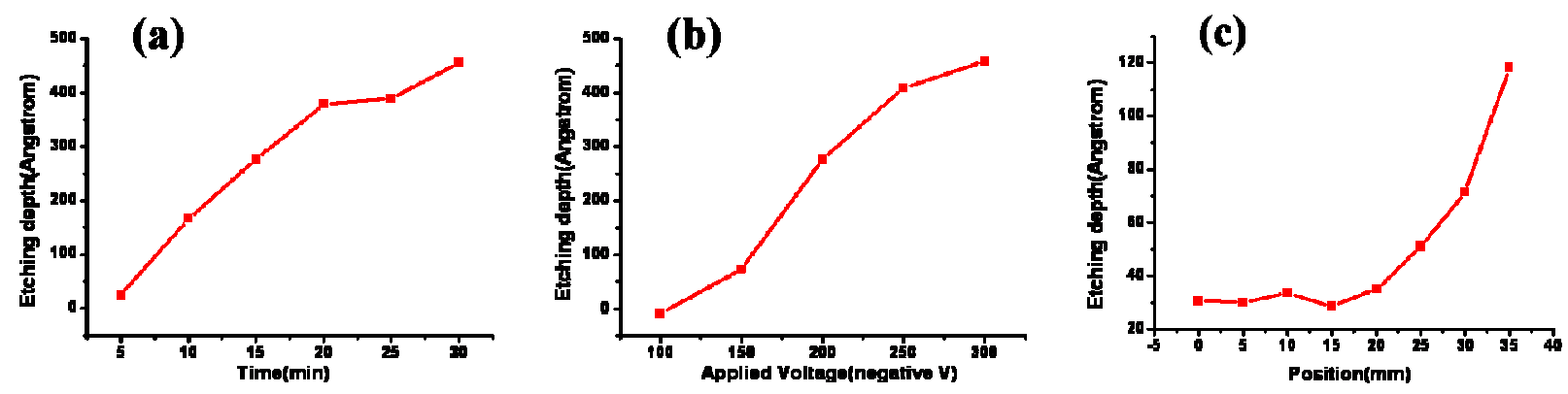

FIG. 1. Plasma etching rate as a function of (a) time at $200 \mathrm{eV}$ bias voltage, (b) bias voltage with fixed $15 \mathrm{~min}$ of etching time, and (c) relative position with $150 \mathrm{~V}$ bias.
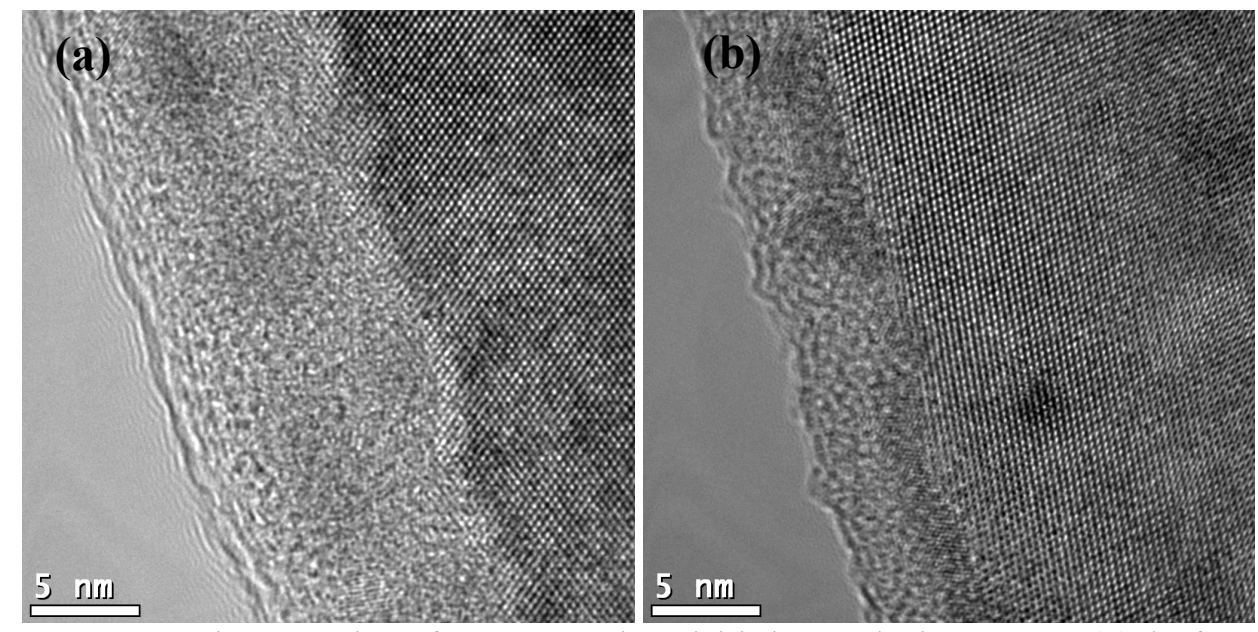

FIG. 2. Micrographs of cross-sectional high-resolution TEM (a) before and (b) after etching with $70 \mathrm{~V}$ bias for $8 \mathrm{~min}$.

TABLE 1. Damage layer thicknesses from various experiments.

\begin{tabular}{|c|c|c|c|c|}
\hline $\begin{array}{c}\text { Damage layer } \\
\text { thickness }\end{array}$ & $\begin{array}{c}\text { Ion energy } \\
(\mathrm{keV})\end{array}$ & $\begin{array}{l}\text { Incidence } \\
\text { angle }\end{array}$ & Condition & Note \\
\hline 5.1 & 3.0 & 75 & $\begin{array}{l}\text { Sample rotation } \\
\text { Liquid nitrogen }\end{array}$ & Barna et al. [2] \\
\hline$\sim 2.4$ & 3.5 & 76 & $\begin{array}{c}\text { cooled } \\
\text { and rotation } \\
\text { Liquid nitrogen }\end{array}$ & Schuhrke et al. [3] \\
\hline$\sim 2.9$ & 5 & 76 & $\begin{array}{l}\text { cooled } \\
\text { and rotation }\end{array}$ & Schuhrke et al. [3] \\
\hline$\sim 2.6$ & 5 & 75 & Sample rotation & Bulle-Lieuwma et al. [4] \\
\hline 4.8 & 3 & 80 & Incidence from [111] & Lee et al. [5] \\
\hline 3.78 & 5 & 75 & Sample rotation & Y.-W. Kim. [1] \\
\hline
\end{tabular}

